\title{
EREBEA
}

Revista de Humanidades

y Ciencias Sociales

Núm. 6 (2016), pp. 11-37

ISSN: 0214-0691

\section{Encuentros improbables: Cervantes y Shakespeare ENTRE BORGES y BuRgESS}

\author{
Zenón Luis-Martínez \\ Universidad de Huelva
}

RESUMEN

En sus biografías sobre Cervantes y Shakespeare, Luis Astrana Marín especuló con un encuentro entre ambos con ocasión de la ratificación en 1605 en Valladolid del Tratado de Londres. Este improbable encuentro ha seguido alimentando ficciones históricas y fantasías literarias. El cruce de caminos entre Cervantes y Shakespeare tiene lugar en torno a la perdida tragicomedia The History of Cardenio (1612?), atribuida a John Fletcher y William Shakespeare. La reconstrucción del diálogo de los dos genios se lleva a cabo aquí a través de lo que sabemos del Cardenio y de sus reescrituras contemporáneas. Además, el encuentro entre Cervantes y Shakespeare se sitúa ante el espejo biográfico y literario de dos grandes de las letras contemporáneas de apellido casi homónimo, Jorge Luis Borges y Anthony Burgess, en un intento de mostrar la capacidad de la imaginación poética para borrar los límites entre la vida y la literatura.

Palabras Clave

W. Shakespeare; M. de Cervantes; J. L. Borges; A. Burgess; Historia de Cardenio.
Abstract

In his biographies of Cervantes and Shakespeare, Luis Astrana Marín conjectured a meeting between these two authors in Valladolid (1605) on the occasion of the ratification of the Treaty of London. This improbable meeting has continued nurturing historical fictions and literary fantasies. Another crossroads between Cervantes and Shakespeare also takes place in the lost tragicomedy The History of Cardenio (1612?), attributed to John Fletcher and William Shakespeare. A reconstruction of the dialogue between these two literary geniuses is attempted here through what we know about Cardenio, as well as through its contemporary rewritings. Moreover, the encounter between Shakespeare and Cervantes is placed in the biographical and literary mirror of two major names of contemporary letters with almost identical surnames, Jorge Luis Borges and Anthony Burgess, in an attempt to prove the power of the poetic imagination to blur the boundaries between life and literature.

\section{KEYwords}

W. Shakespeare; M. de Cervantes; J. L. Borges; A. Burgess; Historia de Cardenio. 

En la segunda parte de sus memorias, titulada You've Had Your Time (1990), el escritor británico Anthony Burgess (1917-93) relata un peculiar encuentro con su admirado y casi homónimo colega el argentino Jorge Luis Borges (18991986). Este tuvo lugar durante el World Shakespeare Congress de 1976, el primer congreso de la ISA (International Shakespeare Association), en Washington D. C. Burgess nos recuerda que la asociación aprovechó la coincidencia del bicentenario de la Declaración de Independencia de los Estados Unidos con el 360 aniversario de la muerte de Shakespeare para dotar de cierta aura mística la puesta en marcha de un evento académico que desde entonces se ha celebrado con periodicidad quinquenal y sin interrupción-el último, en Londres y Stratford-upon-Avon en 2016. En aquella ocasión, las tres ponencias plenarias corrían a cargo del profesor inglés Alistair Cooke y de los citados Borges y Burgess. El escritor bonaerense había llamado en alguna ocasión de forma humorística al de Manchester "el Borges mancuniano". Burgess fue invitado a una fiesta en honor de Borges en la Embajada Argentina, y allí coincidieron por primera vez. Del encuentro sabemos lo que Burgess nos cuenta: era necesario evitar "a los espías alrededor en busca de palabras incriminatorias" ["spies around listening for incriminatory words"]. Estamos, no olvidemos, en los meses posteriores al golpe de estado del general Jorge Rafael Videla que derrocó a María Estela Martínez de Perón el 24 de marzo de 1976. La solución de ambos fue comunicarse en inglés antiguo, mediante un recitado antifonal del conocido "Himno de Cædmon", un breve poema anglosajón conservado en varias versiones dialectales que celebra la creación $(\mathrm{OE}$ frumsceaft):

\author{
Nū wè sculon herigean \\ meotodes meahte \\ weorc wuldorfæder, \\ èce drihten, \\ Hē ǣrest sceōp \\ heofon tō hrōfe, \\ pā middangeard \\ èce drihten, \\ firum foldan,
}

heofonrīces weard, ond his mōdgepanc, swa hē wundra gehwæs, or onstealde. eorðan bearnum hālig scyppend; moncynnes weard, xfter tēode Frēa ælmihtig. 
[Alabemos ahora al Guardián del Cielo / el poder del Señor, los designios y obras / del Padre Glorioso, pues Él, el Eterno, / a todo prodigio diole comienzo. / Él al principio, Santo Hacedor, / el cielo creó para techo de hombres. / Luego la tierra el Eterno Señor, / el Guardián de las gentes / hizo y dispuso, / la que habitan los hombres, el Dios Poderoso. $]^{1}$

Burgess apuntala con ironía que esta ocurrencia, que mantuvo a los espías alerta, puede entenderse como "un triunfo de la erudición" ["a triumph for scholarship"] ${ }^{2}$. La vocación políglota de ambos escritores encuentra en la lengua anglosajona un elemento coincidente. Burgess había impartido cursos de lingüística en la Universidad de Birmingham. El autodidacto Borges halló una de sus grandes pasiones en el inglés antiguo, cuya literatura enseñó en la Universidad de Buenos Aires entre 1956 y 1967. En la transcripción conservada de su curso de literatura inglesa de 1966, Borges cuantificó el legado literario de Cædmon en "unos versos mediocres ... y una hermosa leyenda" ${ }^{3}$. Ciertamente, la discutible mediocridad de sus nueve versos conservados no hace sombra a la conocida leyenda, relatada por Beda el Venerable en su Historia ecclesiastica gentis anglorum (c. 731). En ella, el pastor analfabeto Cædmon aprende el arte de versificar en un sueño milagroso, tras el cual compone el primer poema cristiano en lengua inglesa, siguiendo las convenciones métricas y formulaicas de la poesía pagana ${ }^{4}$. Como ha señalado recientemente Daniel Donoghue, Cædmon confirió a los epítetos épicos de la poesía anglosajona un nuevo carácter sacro, y de ese modo convirtió su himno a la creación en un acto de creación en sí mismo: el de una nueva especie poéticas 5

Por más que todo en este encuentro resulte verificable, la anécdota está impregnada de cierta improbabilidad, sin duda efecto del carácter remoto de la lengua elegida, así como del elemento onírico y legendario de la leyenda que da pie a los versos de Cædmon. Como en las mejores narraciones borgianas, la vida

1 Cito la versión en dialecto sajón occidental que se recoge en el la traducción al inglés antiguo de la Historia Ecclesiastica Gentis Anglorum, de Beda el Venerable. Véase "Bede's Account of the Poet Cædmon”, en A Guide to Old English, eds. Bruce Mitchell y Fred Robinson. Oxford: Blackwell, 1992, 5a edición, p. 222. Traducción española de Luis Lerate y Jesús Lerate, en Beowulfy otros poemas anglosajones. Madrid: Alianza, 1986, p. 170.

2 Antony Burgess, You've Had Your Time, Being the Second Part of the Confessions of Anthony Burgess. Londres: Heinemann, 1990, p. 336.

3 Martín Arias y Martín Hadis, eds. Borges, profesor: Curso de literatura inglesa en la Universidad de Buenos Aires. Buenos Aires: Emecé, 2000, p. 94.

4 Beda, Historia Ecclesiastica Gentis Anglorum, IV.22, texto electrónico en The Latin Library: $<$ http://www.thelatinlibrary.com/bede/bede4.shtml\#24>.

5 Daniel Donoghue, Old English Literature: A Short Introduction. Oxford: Blackwell, 2004, pp. $58-59$. 
queda expuesta a lo inverosímil y a lo inesperado. Del mismo modo en que, en un conocido relato, Pierre Menard usurpaba las palabras de Miguel de Cervantes para conferirles un nuevo significado, Burgess y Borges ventriloquizan a Cædmon para convertir su incomprensible diálogo en un alegato del poder de la erudición literaria frente a las presiones (y las opresiones) de la realidad ${ }^{6}$.

No resulta extraño que el autor y coprotagonista de la narración de este singular encuentro literario lo sea también de un relato breve que pone la ficción histórica al servicio de otro encuentro, el de Miguel de Cervantes y William Shakespeare, que ya ha adquirido estatus de fantasía literaria. "A Meeting in Valladolid", el cuento que abre la colección The Devil's Mode (1989), comparte con el encuentro en Washington el detalle de la irrupción de un idioma inesperado que, a modo de lingua franca, se presta a facilitar un primer acercamiento entre un hispanohablante y un angloparlante. Mientras que Burgess asume cierto conocimiento del árabe para Cervantes por sus cinco años de cautiverio en Argel, con Shakespeare debe inventar una circunstancia que le otorgue cierta familiaridad con el idioma:

I was no slave or hostage but I learned somewhat of [the Moorish tongue]. That was when I accompanied my lord of Southampton on the mission to Rabat, a failed mission to buy Arab horses for my lord Essex's campaign in Ireland.

[No fui esclavo ni cautivo, pero aprendí algo de la lengua de los moros. Fue cuando acompañé a mi señor el Conde de Southampton en su misión a Rabat, una empresa fallida para comprar unos caballos árabes para la campaña de Irlanda de mi señor el Conde de Essex]. ${ }^{7}$

Pero la pincelada lingüística que cohesiona ambos relatos no cumple necesariamente la misma función. En el primero, lo que inicialmente se antoja una humorada acaba revistiendo un encuentro prosaico de una fuerza literaria casi mítica. En el segundo, por el contrario, el recurso al árabe, a través de la equiparación del cautiverio real de Cervantes con el episodio imaginario de la expedición de Shakespeare a Rabat junto a su mecenas (y para muchos biógrafos, amante) Henry Wriothesley, Conde de Southampton, contribuye a anclar en la apariencia de verdad un episodio que algunos establecieron como conjetura histórica y la mayoría descarta por imposible. Ambos encuentros, sin embargo, coinciden en poner a la historia cara a cara con la ficción. Por diversas

6 Véase Jorge Luis Borges, "Pierre Menard, autor del Quijote", en Ficciones (1944). Obras completas, vol. 1. Barcelona: RBA / Instituto Cervantes, 2005, pp. 444-450.

7 Anthony Burgess, "A Meeting in Valladolid", en The Devil's Mode. Londres: Hutchinson, 1989, p. 10, traducción propia. 
razones y circunstancias de sus trayectorias literarias, Borges, Burgess, Cervantes y Shakespeare se erigen en maestros de esta confrontación. En el caso de los dos últimos, su consideración como máximas cumbres de la literatura universal ha añadido a su producción literaria su condición de personajes en los que lo verificable de sus biografías se mezcla inevitablemente con la ficción y el mito. La construcción narrativa y crítica de un más que improbable encuentro entre Cervantes y Shakespeare en lo vital y en lo literario se ha ido cimentando a lo largo de los años hasta llegar a 2016, año en el que las celebraciones del cuarto centenario de la muerte de ambos han convertido este intercambio más imaginario que real en un motivo de especulación casi obligado. Se propone aquí un repaso de algunas claves de este cruce de trayectorias: Borges y Burgess, entre otros, oficiarán de maestros de ceremonias de este conjunto de conjeturas.

\section{Astrana y "LOS HeChos" / Burgess y LA FicCión}

La leyenda de que Cervantes y Shakespeare pudieran haber llegado a conocerse se la debemos a Luis Astrana Marín (1889-1959), biógrafo de ambos, estudioso del primero y traductor de las obras completas del segundo. Como bien muestra Montero Reguera en una excelente semblanza de Astrana, las figuras de Cervantes y Shakespeare se entrecruzan con frecuencia en la obra del escritor y erudito conquense $^{8}$. Para traducir a Shakespeare, Astrana evoca constantemente los logros de la literatura española del Siglo de Oro y resalta la pertenencia de uno y otro a la "egregia familia de los autodidactos". Pero, sobre todo, investiga todos los recovecos posibles de la conjetura en torno a las circunstancias que pudieron juntar los destinos de los dos autores entre 1604 y 1605. En su biografía de Shakespeare (1941), escribe ya Astrana sobre la embajada encabezada por don Juan Fernández de Velasco, quinto Duque de Frías y undécimo Condestable de Castilla, que en agosto de 1604 llevó a Londres a los españoles con el objetivo de negociar la paz entre España y la Inglaterra de Jacobo I, un año después de la muerte de su antecesora Isabel I. El rey ordena que doce de los actores de la Compañía de Siervos de su Majestad (la compañía de Shakespeare) se trasladen a las dependencias reales de Somerset House para asistir y entretener a los españoles. Astrana conoce la constancia documental de la comunicación a Shakespeare y a otros de que

8 Véase José Montero Reguera, "Luis Astrana Marín, traductor de Shakespeare y biógrafo de Cervantes", en Entre Cervantes y Shakespeare: Sendas del Renacimiento / Between Shakespeare and Cervantes: Trails along the Renaissance, eds. Zenón Luis-Martínez y Luis Gómez Canseco. Newark: Juan de la Cuesta, 2006, pp. 113-137. esp. pp. 131-135).

9 Luis Astrana Marín, Vida ejemplar y heroica de Miguel de Cervantes Saavedra con mil documentos hasta ahora inéditos y numerosas ilustraciones y grabados de época. Madrid: Instituto Reus, 1948-1958, vol. II, p. 158. Utilizo el texto electrónico de la Biblioteca Virtual Miguel de Cervantes, <http://www.publiconsulting.com/pages/astrana/index.htm>, último acceso de 8 de octubre de 2016. 
atendieran al embajador, y aunque también nos recuerda que "los servicios del poeta y de sus camaradas no consistieron en representaciones escénicas, sino en formar el séquito de los españoles", no puede resistirse a aventurar "que hubiera en el palacio alguna representación teatral" ${ }^{10}$. El documento en cuestión es una entrada en los Registros del Tesoro a los actores de la Compañía de Siervos de su Majestad Augustine Philips y John Heminges por los servicios prestados al embajador español entre el 9 y el 27 de agosto de 1604 en Somerset House. El nombre de Shakespeare no aparece mencionado en el documento, pero es difícil pensar en su ausencia teniendo en cuenta el número de actores que estuvo allíi ${ }^{11}$. Más allá del dato, el papel de los biógrafos shakesperianos posteriores se ha limitado a llenar el vacío con conjeturas probables. Lois Potter, por utilizar un ejemplo reciente, señala el atractivo de esta misión para los actores, que habrían aprendido mucho del contacto con los espańoles de cara a representar sus maneras y costumbres sobre las tablas. Y también la oportunidad que esta embajada hubiese brindado a Shakespeare para familiarizarse con la lengua española ${ }^{12}$. Astrana prefirió ir más allá e imaginar que, teniendo en cuenta la fama del dramaturgo y las aficiones literarias del noble español, no es descabellado pensar que "Shakespeare y el duque de Frías entablaran amistad o al menos se conocieran más que superficialmante"13.

El siguiente episodio que relaciona a Shakespeare con España es, de nuevo según Astrana, un viaje en el que el poeta pudo haber acompañado a Stephen Bellot, un francés aprendiz del oficio de confeccionar pelucas y postizos en el taller de un compatriota hugonote, Christopher Mountjoy, en cuya casa Shakespeare se alojaba como inquilino por entonces. En la biografía de Shakespeare, este episodio sería independiente del posterior viaje a Valladolid, para el que esta fuente embarca a "750 ingleses que acompañaron, deseosos de conocer a España, al almirante de Inglaterra, lord Howard, en abril-junio de 1605"14. Sin embargo, las conjeturas vertidas aquí se reelaborarán de forma definitiva en los tomos VI y VII de la monumental y controvertida Vida ejemplar y heroica de Miguel de Cervantes Saavedra (1948-1958). Ahora, la noticia de 1612 sobre el supuesto viaje de Bellot "siete años antes" pasa a enmarcarse en la embajada de Charles Howard

10 Luis Astrana Marín, Vida inmortal de William Shakespeare. Madrid: Ediciones Españolas, 1941, pp. 294-295.

11 El documento en cuestión se encuentra en el Rollo 41, Legajo 388, de la Audit Office, Declared Accounts. Treasurer of the Chamber, y aparece reproducido fotográficamente y transcrito en Ernest Law, Shakespeare as Groom of the Chamber. Londres: G. Bell \& Sons, 1910, pp. 21-22. Véanse pp. 21-31 para una interpretación más detallada de este documento.

12 Lois Potter, The Life of William Shakespeare: A Critical Biography. Oxford: Wiley-Blackwell, 2012, pp. 307-308.

13 Astrana Marín, Vida inmortal de William Shakespeare, p. 294.

14 Astrana Marín, Vida inmortal de William Shakespeare, p. 296. 
de Efingham, Conde de Nottingham, para refrendar la paz con los españoles en la primavera de 1605. Y los motivos del francés para embarcarse en una expedición de 506 ingleses sería acompañar a Shakespeare, que se encontraría con escaso margen de dudas entre ellos. La coincidencia de la embajada con el bautismo del primogénito del rey Felipe III, el posible encargo a Cervantes, entonces en Valladolid, de una de las relaciones de los festejos de esos días, y la presencia de Don Quijote y Sancho en una de las pantomimas celebradas en los festejos hicieron pensar a Astrana que por esos días Shakespeare pudo tener no sólo sus primeras noticias del Quijote sino también un encuentro con el español. La profusa relación de Astrana a partir de la documentación existente-relaciones, cartas, etc.—no puede concluir más que con un deseo:

Y de Shakespeare, ¿qué se sabe? ¡Lástima que no haya asidero en que fundamentar una entrevista de Cervantes (autor de La española inglesa) y Shakespeare (escenificados de la Historia de Cardenio) en Valladolid ¡Dies magna para las Letras, si se descubriese! El mejor español junto al mejor inglés. ${ }^{15}$

Montero Reguera ve en la conjetura de Astrana "un ejemplo paradigmático" de su método biográfico: "algunos datos ciertos, muchas probabilidades, acumulación de datos y documentación no directamente relacionados [...], falta de pruebas fehacientes"16. Jean Canavaggio, gran admirador de Astrana, nos insta a dejar de soñar, a pesar de la tentación que supone aventurar "un encuentro en la cumbre de los dos gigantes de las letras" ${ }^{17}$.

Desechado por incierto el encuentro en el ámbito de la historia, la búsqueda de vínculos en la esfera de la ficción literaria también ha girado en torno a las embajadas de paz de Londres y Valladolid. La localización y las alusiones españolas de All's Well that Ends Well (1603) han puesto a más de un estudioso shakesperiano en la pista de una posible relación de la obra con el cambio de política de Jacobo I (James) con respecto a España desde su llegada al trono y su emblemática coronación el 25 de julio de ese año, día de Santiago (St. James), santo patrón de la todavía archienemiga España ${ }^{18}$. Como nos recuerda Richard Wilson, la fecha

15 Astrana Marín, Vida ejemplar y heroica de Miguel de Cervantes Saavedra, vol. VII, p. 58. La recreación completa de Astrana de este episodio puede consultarse en el capítulo LXXII, pp. 7-63.

16 Montero Reguera, "Luis Astrana Marín", p. 133.

17 Jean Canavaggio, Cervantes: En busca del perfil perdido. Madrid: Espasa Calpe, 1992, 2a ed., p. 248.

18 Véase Willem Schrickx, "Elizabethan Drama and Anglo-Dutch Relations", en Reclamations of Shakespeare, ed. A. J. Hoenselaars. Amsterdam: Rodopi, 1994, pp. 21-32, esp. pp. 29-31, y "All's Well that Ends Well in Its Historical Context", Shakespeare Jabrbuch, no 131 (1995), pp. 106-115. Y más recientemente Richard Wilson, ““To Great St Jaques Bound”: All's Well that Ends Well in 
de la coronación replicaba la de las nupcias de María Tudor con Felipe II en la Catedral de Winchester exactamente 48 años antes. Las cuatro referencias en la obra a Helena como peregrina a Santiago de Compostela abren dicha pista. En cualquier caso, en la declaración de intenciones de Helena nos encontramos con el único viaje (imaginario) de Shakespeare a España: "I am Saint Jacques' pilgrim, thither gone" 19 .

Si la obra de Shakespeare anuncia una mirada amable hacia el mundo católico por parte del nuevo rey de Inglaterra, y si su representación hizo más agradable la estancia de la embajada española de 1604, es entonces Shakespeare quien abre un camino que después se ensancha con el conocimiento que los ingleses tuvieron un ańo después de la figura de don Quijote tanto en los entremeses de Valladolid como a través de las páginas de su primera edición. Insiste Wilson en que, por una casualidad digna de Borges, una obra de Shakespeare con una fuerte conexión española y católica se representó frente a aquellos que meses después serían algunos de los primeros lectores de Cervantes ${ }^{20}$. Borges, que escribió ficciones sobre Shakespeare y Cervantes por separado, no exploró ni esta ni otra posibilidad de encuentro shakesperiano-cervantino en su obra. Su homónimo Burgess sí lo hizo, como ya se ha indicado, y Valladolid proporciona a la ficción en su relato lo que la historia y la biografía no han podido demostrar: la conversación cara a cara entre los dos genios.

Con todo, nada es en Burgess como Astrana o Canavaggio habrían deseado. Su relato deshace la fantasía de que una reunión en la cumbre habría sido un camino de rosas, o que la cortesía y la bonhomía habrían sido cualidades indisociables del genio literario. Burgess apuesta por unos personajes decididamente humanos, y en consecuencia presos de todos los prejuicios que con seguridad habrían aflorado entre sus compatriotas y contemporáneos alrededor de una embajada como la de los ingleses en Valladolid a comienzos del XVII . ${ }^{21}$ La delegación inglesa llega en los albores del verano de 1605 para firmar un tratado de paz en el que nadie cree. La tensión entre ambas delegaciones se masca en el ambiente. El pueblo mira con suspicacia y hostilidad a esos bárbaros protestantes que no pueden ser otra cosa que enemigos. Los ingleses se atracan de huevos con torreznos, contemplan con escepticismo los espectáculos taurinos, y se solazan con jóvenes de ambos sexos

Shakespeare's Spain”, en Entre Cervantes y Shakespeare, eds. Luis-Martínez y Gómez Canseco, pp. $15-37$.

19 All's Well that Ends Well, en The Riverside Shakespeare, ed. G. Blakemore Evans. Boston: Houghton Mifflin, 1987, 3.4.4, p. 524. Todas las citas de la obra de Shakespeare proceden de esta edición.

20 Wilson, “To Great St Jaques Bound”, p. 28.

21 Para una lectura de este cuento en torno a Shakespeare como personaje de ficción, véase Paul Franssen, Shakespeare's Literary Lives: The Author as Character in Fiction and Film. Cambridge: Cambridge University Press, 2016, esp. pp. 216-219. 
en las tórridas noches españolas. Entre ellos están los cómicos, los Siervos de su Majestad, cuya misión es, según el actor Richard Burbage, la de "untar algo de miel sobre el insípido pan" de la $\mathrm{paz}^{22}$. Un displicente Shakespeare que sufre problemas estomacales decide representar para los españoles unas escenas del sangriento Tito Andrónico, con "más sangre (de cerdo, comprada en un mercado local) que verso blanco" ${ }^{23}$. Los espańoles no dan crédito de tanta brutalidad. Y los ingleses encuentran insípida la dramaturgia de Lope. Nada presagia que la cita pueda convertirse en un ejemplo de empatía e interculturalidad. En esto don Manuel, un noble espańol conocedor de Inglaterra y de su idioma, y admirador de Hamlet, propicia un encuentro entre Shakespeare y Cervantes, vecino entonces de Valladolid, en casa de este. El "encuentro en la cumbre" no puede salir peor. No entienden la lengua del otro, lo intentan primero con un árabe rudimentario, y se valen finalmente de don Manuel como intérprete. Sus principios literarios son incompatibles. Cervantes reprocha a Shakespeare su inclinación protestante hacia el tema trágico de la predestinación. Como desafío, Shakespeare prepara para la noche siguiente una dramatización cómica de Hamlet en la cual Sir John Falstaff, el obeso, borracho y holgazán caballero de la historia de Enrique $I V$, se encuentra con el príncipe de Dinamarca durante su viaje a Inglaterra y se lo lleva de parranda. Tras la obra, un enfadado Cervantes reprocha a Shakespeare haber copiado a Hamlet y Falstaff de don Quijote y Sancho. Shakespeare le replica que ambos estaban en sus obras mucho antes de que existiera ese libro que parece interminable e imposible de adaptar a los escenarios. Años después, Cervantes muere, un 22 o un 23 de abril de 1616, habiendo borrado de su memoria al poeta bárbaro de la pérfida y ya menos amiga Albión. Shakespeare muere días después, un 3 de mayo, habiendo leído la traducción de Shelton y reconociendo finalmente el genio narrativo del espańol y la superioridad literaria de la novela:

No leyó Don Quijote hasta 1611, el año de la traducción de la obra por Shelton y también el año de aparición de la Biblia del Rey Jacobo. Hay referencias al demacrado caballero y al gordo escudero en los dramas de Ben Jonson y Beaumont y Fletcher, pero no en las obras de Shakespeare. Cuando cayó finalmente enfermo en 1616 estaba todavía dando vueltas a que Cervantes iba un paso por delante de él en el dominio de la creación de un personaje universal. Murió el mismo día que Cervantes, pero como el calendario español

22 "It is to be a slow negotiation of $p a z$ at Valladolid. The King's Men are here to spread a sort of honey on the dull bread of it": Burgess, A Meeting in Valladolid, pp. 5-6.

23 "more blood (pig's, locally bought) than blank verse": Burgess, A Meeting in Valladolid, p. 11. 
iba diez días por delante del británico, puede decirse que hasta en morirse Cervantes le adelantó. ${ }^{24}$

Esa querencia tardía de Shakespeare por el género novelístico imaginada aquí por Burgess nos devuelve, quizás ahora casi por casualidad, a Astrana y a su tendencia a vislumbrar en las obras últimas de Shakespeare-Pericles, Cymbeline, The Winter's Tale y The Tempest - un encuentro imaginario con el también último Cervantes, el de Los trabajos de Persiles y Sigismunda: "Siempre que pensamos en estas últimas obras viene a nuestra imaginación la postrera novela de Cervantes [...] Vagos recuerdos de la vida de sus autores mezclados a visiones fantasmagóricas. Naufragios, peregrinaciones, aventuras en islas. El estilo se despoja de toda gala superflua. Las imágenes (rara paradoja imaginar sin imágenes) escasean. Un ascetismo rígido lo inunda todo. Empero la palabra es más justa y precisa, y el pensamiento más hondo y elevado"25. Algunos han recogido con posterioridad el guante de Astrana y de Burgess al señalar la tendencia hacia la narratividad de un Shakespeare que, si siguiésemos las apreciaciones de Longino sobre Homero, revelarían a un autor viejo frente a la propensión de la juventud por la acción y la épica:

Por la misma razón, creo yo, al estar la Ilíada escrita en la plenitud de su espíritu, concibió el cuerpo entero del poema de modo dramático y belicoso, el de la mayor parte de la Odisea, en cambio, de modo narrativo, que es el propio de la vejez. De ahí que, en la Odisea, podría compararse a Homero con un sol en su ocaso, cuya grandeza subsiste sin la intensidad. ${ }^{26}$

24 "He did not read Don Quixote until 1611, the year of the translation of the work by Shelton and also of the appearance of the King James Bible. There are references to the lean knight and his fat squire in the plays of Ben Jonson and Beaumont and Fletcher, but none in the plays of Shakespeare. When he fell into his last illness in 1616 he was still brooding about Cervantes's having stolen a march on him in the domain of the creation of a universal character. He died on the same day as Cervantes, but as the Spanish calendar was ten days ahead of the British, it may be said that even in dying Cervantes stole a march": Burgess, "A Meeting in Valladolid", p. 21.

25 Astrana Marín, Vida Inmortal de William Shakespeare, pp. 271-272.

26 Longino, De lo sublime, ed. Manuel Pérez López. Madrid: Dykinson, 2011, p. 101. Para una lectura comparada de los últimos dramas de Shakespeare con el Persiles de Cervantes en torno a la teoría y práctica del arte de narrar, véase Zenón Luis-Martínez, "Preposterous Things Shown with Propriety: Cervantes, Shakespeare, and the Arts of Narrative", en Entre Cervantes y Shakespeare: Sendas del Renacimiento, eds. Luis-Martínez y Gómez Canseco, pp. 259-305. También, de modo más general, Valerie Wayne, "Don Quixote and Shakespeare's Collaborative Turn to Romance”, en The Quest for Cardenio: Shakespeare, Fletcher, Cervantes and the Lost Play, eds. David Carnegie y Gary Taylor. Oxford: Oxford University Press, 2012, pp. 217-238. 
En la (creo que deliberadamente) errónea datación en 1611 de The History of the Valorous and Wittie Knight-Errant Don-Quixote of the Mancha (1612), la traducción de la primera parte de la novela de Cervantes por parte del irlandés Thomas Shelton, Burgess persigue una coincidencia con otro hito gigantesco en la cultura y las letras inglesas, la aparición de la Biblia del Rey Jacobo, o King James Bible. Sería este un nuevo encuentro imaginario que pudiese haber tenido lugar en la mente, o en la memoria de Shakespeare. Astrana sitúa esta lectura en su momento más probable, ya en 1612, para modelar a un Shakespeare que, influido por la narración cervantina, ideó junto a Fletcher la hoy perdida The History of Cardenio (1613). Pero Burgess deja a Cardenio fuera, seguramente porque lo que importa en su relato, en lo que respecta a la comparación de los géneros, es la idea de una obra cervantina cuyo poder se cifra en su resistencia a la adaptación dramática ${ }^{27}$.

Parece que la ficción de Burgess acaba poniendo la fantasía biográfica de Astrana en su justo lugar. Para el erudito español, en las figuras de Shakespeare y Cervantes se funden de una manera tan inseparable la excelencia personal y literaria que un encuentro entre ambos no habría hecho más que potenciar "un vigor de espíritu, una moralidad, una ejemplaridad, un arte, en fin, tan sobrehumano" que distingue a ambos del resto ${ }^{28}$. Para Burgess, sin embargo, vida y obra permanecen razonablemente separadas. Su relato nos sugiere que las condiciones de la Paz de Valladolid no fueron quizás las más propicias para un encuentro ideal, recordándonos de paso que las sendas que juntan a los dos escritores solamente pueden tener lugar en sus textos. Aunque en lo que respecta a Cervantes y a Shakespeare, la senda más segura es de nuevo una senda perdida.

\section{La historia de Cardenio: Fletcher y Theobald entre Cervantes y Shakespeare}

Aunque el encuentro en Valladolid no sea más que fantasía, lo que sí parece más probable es que algún ejemplar de la primera parte del Quijote acompañara de vuelta a los ingleses, y que esta visita inaugurase la larga y fructífera historia de influencia de Cervantes en Inglaterra. Ya en 1607, los dramaturgos George Wilkins y Thomas Middleton mencionan en sus obras The Miseries of Inforst Marriage y Your Five Gallants la idea de luchar contra molinos de viento ${ }^{29}$.

27 A la pregunta de Shakespeare sobre si el Quijote puede transformarse en una obra de teatro, Don Manuel, el traductor y propiciador del encuentro en el relato de Burgess, contesta: "No se puede. Su longitud es su virtud. No puedes comprimir tan largo viaje en el discurrir de dos horas" [It cannot. Its length is its virtue. You cannot encompass so long a journey in your two hours' traffic]: Burgess, "A Meeting in Vallodolid", p. 17. La expresión "two hours' traffic" la usó Shakespeare en la tragedia Romeo and Juliet, Prólogo, 12, p. 1058.

28 Astrana Marín, Vida inmortal de William Shakespeare, p. 151.

29 George Wilkins, The Miseries of Inforst Marriage. Londres: George Vincent, 1607, sig. F1'; Thomas Middleton, Your Five Gallants. 1607, ed. Ralph Alan Cohen and John Jowett, en The 
También en 1607 Francis Beaumont escribió The Knight of the Burning Pestle [El caballero del majador ardiente], una obra que mezcla comedia urbana y sátira de los libros de caballerías a través de Rafe, un sirviente que debe representar en una obra dentro de la obra el papel de caballero andante. El dramaturgo Ben Jonson, amigo y rival de Shakespeare, también menciona a Amadís de Gaula y a Don Quijote en Epicoene, or the Silent Woman, publicada por primera vez en 1616, aunque la comedia aparece ya listada en los registros de la Honorable Compañía de Impresores londinense en el año $1610 .^{30}$

La publicación en 1612 de The History of the Valorous and Witty Knight Errant Don Quixote de la Mancha es un capítulo más del entusiasmo que desde años anteriores habían generado en Inglaterra las letras hispanas. En esta primera traducción, concluida posiblemente en los Países Bajos en torno a 1607 por el católico irlandés Thomas Shelton, no hay una sola referencia a Miguel de Cervantes ni en su página de título ni en su interior, cuyo nombre o autoría de la obra no parece resultar relevante. Un año después, el 20 de mayo de 1613, la Compañía de Siervos de Su Majestad representa en la corte una obra titulada "Cardenno", o "Cardenna" [sic.] entre una veintena de obras, principalmente de John Fletcher y del propio Shakespeare, con motivo de las bodas de la Princesa Isabel y el Duque Federico, Elector del Palatinado. Entre las obras de Shakespeare elegidas para estos festejos están Othello (1604) The Winter's Tale (1610-1611) y The Tempest (1611). Otro documento da cuenta de que Cardenno volvió a representarse un mes después, esta vez con ocasión de la visita a palacio del embajador del Duque de Saboya. El título parece apuntar con poco margen de duda a Cardenio, el loco enamorado que Don Quijote y Sancho encuentran en Sierra Morena allá por el capítulo 23 de la primera parte. Sin embargo, la obra nunca se publicó ni de forma exenta ni en colecciones de Shakespeare o de Fletcher ${ }^{31}$.

El misterioso título reaparece cuarenta años después. En 1653 el librero Humphrey Moseley registra un manuscrito con un título y una autoría llamativos: "The History of Cardenio, by $\mathrm{M}^{\mathrm{r}}$ Fletcher. \& Shakespeare" [La historia de

Collected Works of Thomas Middleton, gen. eds. Gary Taylor and John Lavagnino, pp. 594-636. 4.6.7-8, p. 626.

30 Véase, entre otros, J.A.G. Ardila, "The Influence and Reception of Cervantes in Britain”, en The Cervantean Heritage: Reception and Influence of Cervantes in Britain, ed. J.A.G. Ardila. Londres: MHRA / Maney, 2009, pp. 2-31. esp. pp. 3-4.

31 Para los pormenores en torno a The History of Cardenio refiero al lector a fuentes recientes que dan además cuenta de las discrepancias de la crítica en torno a este asunto: Ángel-Luis Pujante, "El Cardenio, o los avatares de una obra perdida", en Monteagudo no 10 (2005), pp. 51-63; Roger Chartrier, Cardenio entre Cervantes et Shakespeare. París: Gallimard, 2011. Cito esta obra de su traducción al inglés (también está traducida al español): Cardenio between Cervantes and Shakespeare: The Story of a Lost Play, trans. Janet Lloyd. Londres: Polity, 2013. Véase también Gary Taylor, "The History of The History of Cardenio", en The Quest for Cardenio, eds. Carnegie y Taylor, pp. 11-61. No puedo hacer más aquí que resumir estas circunstancias, y mi relato deriva de las fuentes citadas. 
Cardenio, por Maese Fletcher. Y Shakespeare]. Entre noviembre de 1611, fecha de estreno en la corte de The Tempest, su última obra en solitario, y su muerte el 3 de mayo de 1616, Shakespeare colaboró con Fletcher en la composición de dos obras, Henry VIII (1612-1613) y The Two Noble Kinsmen (1613), por lo que la asociación de ambos para el Cardenio no resulta sorprendente. Además, la noticia de la existencia del manuscrito la firma un librero respetable, que había publicado en 1647 una edición infolio de las obras de Fletcher, y que se jactaba por entonces de poseer más de cincuenta inéditos de la antigua Compañía de Su Majestad.

Tres cuartos de siglo después, en 1728, Lewis Theobald publica Double Falsehood; or, The Distress"d Lovers, obra que había cosechado cierto éxito en 1727 en el Teatro Real de Drury Lane en Londres ${ }^{32}$. Theobald fue un dramaturgo mediocre, pero un notable editor y estudioso de la obra de Shakespeare. En el "Prefacio" a Doble falsedad, Theobald afirma estar en posesión de al menos tres manuscritos de una obra desconocida de Shakespeare, uno de los cuales habría sido medio siglo antes propiedad del actor Thomas Betterton. La obra habría sido un regalo de Shakespeare "a una hija natural suya, por cuya causa la escribió en tiempos de su retirada de los escenarios" ["a natural daughter of his, for whose sake he wrote it, in the time of his retirement from the stage"]. Theobald escribe este prefacio para intentar desmentir a aquellos que dudaban de la autoría shakesperiana del original adaptado. Los incrédulos, nos dice, objetan que "aunque la obra pueda tener ciertas semejanzas con Shakespeare, sin embargo el colorido, la dicción, y los personajes están más cercanos al estilo y la manera de Fletcher" ["though the play may have some resemblances with Shakespeare, yet the colouring, diction and characters come nearer to the style and manner of Fletcher"]. Y a pesar de que él no se atreve a tener una opinión definitiva sobre este particular, concluye que "mi parcialidad en favor de Shakespeare me hace desear que todo lo bueno y placentero escrito en nuestro idioma haya surgido de su pluma" ["my partiality for Shakespeare makes me wish that everything which is good or pleasing in our tongue had been owing to his pen"] ${ }^{33}$. No hay mención de la traducción de Shelton, que Theobald parece desconocer. En su biblioteca, al menos, solo había dos ediciones del Quijote en español y una versión inglesa,

32 Utilizo la reciente edición publicada en la tercera serie de The Arden Shakespeare: Double Falsehood or The Distressed Lovers, ed. Brean Hammond. Londres: Methuen, 2010. Existe traducción española: esta edición atribuye la obra a Shakespeare y Fletcher y la publica bajo el título Historia de Cardenio, ed. y trad. Charles David Ley. Madrid: José Esteban, 1987. Sobre esta traducción, véase el estudio de Ángel-Luis Pujante, "Nostalgia for the Cervantes-Shakespeare Link: Charles David Ley's Historia de Cardenio", en The Quest for Cardenio, ed. Carnegie y Taylor, pp. 318-28. Cito aquí de la edición de Hammond y utilizo mis propias traducciones.

33 Theobald, "Preface of the Editor", en Double Falsehood, pp. 168-170. 
la de 1687 de John Phillips, sobrino del poeta John Milton, y considerado por algunos el peor traductor que jamás haya tenido Cervantes ${ }^{34}$.

El éxito de la obra de Theobald se cimienta sobre el prestigio de Shakespeare en su tiempo. En una nota aparecida en el London Journal el 10 de mayo de 1727 se celebra a Theobald como "un nuevo Shakespeare ... bendecido con la fuerza y la genialidad del primero; alguien que por fin pueda librar a nuestros escenarios de las banalidades que lo asolan, para restaurar así el tradicionalmente viril gusto inglés" ["some other Shakespeare ... blest with the Force and Master-Genius of the first; who might be able to deliver the Stage from the Little Follies that now usurp it, and restore the old manly English taste"] ${ }^{35}$. Estos elogios podrían hacernos olvidar que Double Falsehood no es The History of Cardenio. Theobald tampoco es, ni de lejos, un segundo Shakespeare. Es más, hasta los años 60 del pasado siglo, tuvo cierta aceptación la teoría de que Theobald perpetró una falsificación a partir de la invención de los manuscritos, y, aprovechando su conocimiento de editor de Shakespeare, tińó de falsos ecos shakesperianos su propia versión del original cervantino. ${ }^{36}$ Hoy los estudios de atribución y estilometría vuelven a defender como probable la teoría de que Theobald adaptase una obra de Fletcher y Shakespeare en la que sí estaría la huella de la traducción de Shelton de 1612.37

Si Theobald no urdió una falsa adaptación del Cardenio original, entonces habría que considerar su labor de adaptador. Theobald arregló otras dos obras renacentistas: The History of Richard II $(1595,1719)$ de Shakespeare y The Duchess of Malfi (1611), de John Webster, que tituló The Fatal Secret (1735). En ambas se observa la tendencia, propia desde la reapertura de los teatros en Inglaterra en 1660 , de no representar a los autores de la época anterior en su forma original. Se prefiere, por el contrario, a un autor ajustado a la idea neoclásica de decoro. A Shakespeare se le reescribe para desterrar de su obra al poeta bárbaro que, según el nuevo gusto neoclásico, ahoga y desluce al poeta genial que fue. Por eso se pulen sus supuestas impurezas lingüísticas, y se borra o se cambia de sus argumentos

34 Véase sobre esta cuestión Chartrier, Cardenio, p. 129. Esto no quita para que no pueda apreciarse en Theobald el débito de la obra original con Shelton, como bien ha probado, entre otros, Pujante, "El Cardenio", pp. 54-60.

35 Citado por Hammond, "Introduction”, en Double Falsehood, p. 11.

36 Un ejemplo de esta teoría es Harriet C. Frazier, "Theobald's Double Falsehood: A Revision of Shakespeare's Cardenio?”, Comparative Drama vol. 1 (1967), pp. 219-33. La teoría de Frazier fue contestada por John Freehafer, "Cardenio, by Shakespeare and Fletcher", PMLA vol. 84, no 3 (1969), pp. 501-13. Recientemente, los estudios de Tiffany Stern han vuelto a poner en duda la colaboración de Fletcher y Shakespeare. Véase "'The Forgery of some modern Author??: Theobald's Shakespeare and Cardenio's Double Falsehood", Shakespeare Quarterly vol. 62, no 4 (2011), pp. 555-593.

37 Véanse los estudios al respecto en Carnegie y Taylor, eds. The Quest for Cardenio. También Terri Bourus y Gary Taylor, eds., The Creation and Re-Creation of Cardenio: Performing Shakespeare, Transforming Cervantes. New York: Palgrave Macmillan, 2013. 
aquello que queda suelto, inexplicado, o que simplemente no se adapta a la moral y a la estética de una época. La multiplicidad de significados, o la celebrada ambigüedad de sus textos, en definitiva todo aquello que a nosotros nos parece moderno hoy, olía a antiguo en el Neoclasicismo. A Shakespeare se lo vio como genio, pero también como producto de una época ignorante y poco civilizada ${ }^{38}$.

Un ejemplo lo encontramos en la adaptación que el poeta y dramaturgo Nahum Tate realizó en 1681 de una de las tragedias más conocidas de Shakespeare para los teatros londinenses: se trata de King Lear (1605). Había mucho en Shakespeare que resultaba poco apropiado a los nuevos gustos dramáticos. Lo primero era la propia dicción poética shakesperiana, considerada hiperbólica y excesiva. Tate define en su Prefacio el lenguaje de Shakespeare como "un cúmulo de perlas, desencordadas y sin pulir, [pero] tan deslumbrantes en su desorden" ["a Heap of Jewels, unstrung and unpolish"t ... so dazzling in their Disorder"] ${ }^{39}$. Tate confiesa también su desconcierto ante la pasión desatada del viejo rey y la supuesta indiferencia de Cordelia en la primera escena, y consecuentemente expurga del texto los sobrecogedores versos shakesperianos que expresan la ira del rey. ${ }^{40}$ Además de la dicción, sus tramas y sus personajes tampoco resultan adecuados. La locura del rey y la locura fingida de Edgar abruman al adaptador. También la muerte de Cordelia parece a Tate demasiado castigo para su honestidad, y decide por ello cambiar el argumento original, propiciando el

38 Para estas cuestiones refiero al lector de manera general a William Moelwyn Merchant, "Shakespeare 'Made Fit", en Restoration Theatre, eds. John Russell Brown y Bernard Harris. Londres: Edward Arnold, 1965, pp. 195-220; Michael Dobson, The Making of a National Poet: Shakespeare, Adaptation and Authorship 1660-1769. Oxford: Oxford University Press, 1992); Barbara Murray, Restoration Shakespeare: Viewing the Voice. Londres: Associated University Presses, 2001, y a los ensayos de Fiona Ritchie y Peter Sabor, eds. Shakespeare in the Eighteenth Century. Cambridge: Cambridge University Press, 2012.

39 Nahum Tate, The Tragedy of King Lear. 1681, en Sandra Clark, ed. Shakespeare Made Fit: Restoration Adaptations of Shakespeare. Londres: J. M. Dent, 1997, pp. 295-296.

40 Como muestra, léase a Shakespeare: "For by the sacred radiance of the sun, / The mysteries of Hecat and the night; / By all the operations of the sun, / From whom we do exist and cease to be; / Here I disclaim all my paternal care, / Propinquity and property of blood, / And as a stranger to my heart and me / Hold thee from this for ever. The barbarous Scytian, / Or he that makes his generation meses / To gorge his appetite, shall to my bosom / Be as well neighbor'd, pitied , and reliev'd , / As thou my sometime daughter" [ Pues, por el sagrado resplandor del sol, / los misterios de Hécate y la noche, / por toda la influencia de los astros, / que nos dan la vida y nos la quitan, / desisto aquí de todo deber paterno, / de toda vecindad y afinidad de sangre, / y ajena a mi corazón y a mi persona / te proclamo desde ahora para siempre. El salvaje escita, / o aquel que devora a su progenie / para saciar su apetito, encontrará en mi pecho / mayor cobijo, consuelo y compasión / que la que fue mi hija"]: King Lear 1.1.109-120, p. 1256. Y compárese con Tate: "For by the sacred Sun and solemn Night / I here disclaim all my paternal Care, / And from this minute hold thee as a Stranger / Both to my Blood and Favour" ["Por el sagrado sol y la noche solemne / Aquí desisto de mis cuidados paternales / y desde este momento te declaro ajena / a mi sangre y a mis favores"], 1.1, en Clark, ed. Shakespeare Made Fit. 
amor y finalmente el matrimonio entre el virtuoso Edgar y la abnegada princesa. Para nosotros, este cambio argumental sentimentaliza la tragedia y la priva de su irracionalidad y de su misterio. Para Tate, la inserción de "una o dos nuevas escenas, quizás con más éxito que mérito", está encaminada a "corregir la falta de regularidad y probabilidad de la historia" ["a New Scene or Two, of more Success (perhaps) than Merit ... to rectifie what was wanting in the Regularity and Probability of the Tale"]. Regularidad y probabilidad: son estos los principios del decoro clásico que parecen incompatibles con nuestra admiración por la libertad imaginativa de Shakespeare.

Theobald, que sigue la senda de Tate, comparte esa mezcla de devoción y rechazo. El prologuista Philip Frowde sanciona esta tendencia en Double Falsehood con un símil revelador que insiste en la necesidad neoclásica de contener la imaginación desbordante de su admirado modelo:

As in some region where indulgent skies

Enrich the soil, a thousand plants arise

Frequent and bold; a thousand landscapes meet

Our ravish't view, irregularly sweet:

We gaze, divided, no won these, now those;

While all one beauteous wilderness compose.

Such Shakespeare's genius was...

[Como en un paraje donde los generosos cielos / fertilizan la tierra, y mil plantas florecen / audaces y abundantes; donde mil paisajes confrontan / irregularmente hermosos nuestra arrobada vista, / miramos, divididos, ahora estos, ahora aquellos / cómo todos confluyen en uno de salvaje belleza. / Así era el genio de Shakespeare.... $]^{41}$

Perspectivas múltiples, líneas argumentales complejas y desdobladas, duplicidad semántica y una escritura exuberante. Shakespeare es todo eso. Pero mucho de eso The History of Cardenio se lo debe al original cervantino a través de la traducción de Shelton, entre sus capítulos 23 y 36-o, si lo preferimos, entre la tercera y la cuarta parte del volumen original de 1605. Podría recordarse aquí su débito con la tradición sentimental anterior ${ }^{42}$. Pero también es una historia moral, que nos habla de amor, de amistad y de traición, y sobre todo de cómo las pasiones nos esclavizan y nos liberan, de la dignidad y del afán de superación ante las adversidades, del sentido del deber y de la justicia. La sutileza

41 Philip Frowde, "Prologue”, en Theobald, Double Falsehood, 1-7, pp. 181-182.

42 Véase Valentín Núñez Rivera, Cervantes y los géneros de la ficción. Madrid: Prosa Barrocal SIAL, 2015, pp. 207-214. 
psicológica cervantina ha sido señalada por muchos, frecuentemente a la luz de las apreciaciones de Salvador de Madariaga. Para Madariaga, los episodios de Sierra Morena muestran un permanente contraste entre la inteligencia rápida e instintiva de Dorotea y la irresolución híper-reflexiva y cobarde de Cardenio ${ }^{43}$. Finalmente, la narración cervantina está plagada de recursos que enaltecen toda esta complejidad: pistas verdaderas y pistas faltas, interrupciones, un equilibrio permanente entre la acción presente y el flashback narrativo. Baste decir en este sentido que Cardenio es una celebración del arte de contar, de la posibilidad que el cuento ofrece al narrador de librarse de sus propios demonios-los del dolor y la locura.

La posibilidad de estructurar una trama a partir de episodios entretejidos que permitan la confrontación de sus protagonistas es uno de esos aspectos que no habrían pasado desapercibidos a Shakespeare. El refugio de don Quijote y Sancho en Sierra Morena, perseguidos por la Santa Hermandad tras liberar a Ginés de Pasamonte, da ocasión al hallazgo de una mula muerta en un barranco y, junto a la montura, un baúl que contiene dinero y, en palabras de Cervantes, "un librillo de memoria, ricamente guarnecido" donde hay unos poemas de amor que acusan de traición a una dama ${ }^{44}$. Son las pistas que conducen a un Cardenio loco de amor, que confrontará al otro loco enamorado, don Quijote, dispuesto a hacer penitencia de amor por Dulcinea al modo de Amadís por Oriana. Cardenio comenzará así el relato de sus desgracias: su amor por Luscinda, su retraso en pedir su mano, su entrada en servicio del Duque, y la traición de su amigo, el libertino don Fernando, hijo del Duque, quien, después de haber seducido con promesas de matrimonio a la hija de un rico labrador y despachar a Cardenio enredándolo en el negocio de la compra de unos caballos, obtiene para sí mismo el consentimiento del padre de Luscinda. Y el relato se interrumpe para mostrarnos a los dos protagonistas arrastrados por la violencia—cómica, eso sí-de su locura, y para retomarse más tarde con nuevos interlocutores, el cura y el barbero, que asisten a la narración de los esponsales de Fernando y Luscinda y a la entrada en liza de la labradora Dorotea, aún disfrazada de pastor. El cambio de escenario a la posada, donde tendrá lugar el encuentro de los cuatro jóvenes y la resolución de esta y otras intrigas, entre las que asistimos al protagonismo de Dorotea como la menesterosa princesa Micomicona en la burla que intenta devolver a don Quijote a su pueblo, también habría sido tentador para un dramaturgo como Shakespeare.

Poco de esto queda en Double Falsehood, una tragicomedia fiel a las aventuras de Cardenio, y sin embargo deslucida si la comparamos con la exuberancia del

43 Salvador de Madariaga, Guía del lector del Quijote. 1ª ed. 1926, Barcelona: Stella Maris, 2016, pp. 73-101.

44 Miguel de Cervantes, Don Quijote de la Mancha, ed. Instituto Cervantes / Francisco Rico. Barcelona: Galaxia Gutenberg, 2004, p. 275. 
original. Los tres primeros actos tienen lugar en una villa andaluza, y nos presentan primero la doble falsedad de Henriquez (el nuevo nombre de Fernando), quien seduce primero y abandona después a Violante (Dorotea) para fijar su amor en Leonora (la nueva Luscinda), ganando el afecto del padre de ésta y traicionando a su amigo Julio (Cardenio). Pasamos después a las fallidas nupcias de Henriquez y Leonora: antes de ser llevada al altar, Leonora esconde un puñal entre sus vestidos y oculta a Julio tras una cortina. Cuando su padre se dispone a entregar a Leonora en matrimonio, Julio sale de su escondite (haciendo así realidad los deseos reprimidos del Cardenio cervantino) y desvela la falsedad de Henriquez antes de ser retirado por unos sirvientes. Leonora se desmaya, y entre sus ropas se descubre la daga, así como una carta que desvela su intención de quitarse la vida tras la boda. La escenografía del cuarto acto nos muestra "una vista de las montańas". Allí asistimos al desenmascaramiento del disfraz masculino de Violante, a la fugaz locura de Julio, y al encuentro de ambos. Mientras tanto, Henriquez y su hermano mayor se dirigen en busca de Leonora, escondida en un convento. El último acto, que se desarrolla en un refugio en las montañas, propicia el encuentro de los protagonistas, y una reconciliación desprovista de las sutiles intrigas que conducen al desenlace en el Quijote.

El deslucimiento, la brevedad y la simpleza de Double Falsehood son evidentes. Gary Taylor ha señalado que la de Theobald es "media obra", si comparamos con la longitud y la estructura de tragicomedias escritas en el mismo momento que el perdido Cardenio. Media por la brevedad del texto, pero también por la ausencia de un más que posible desdoblamiento de la trama del original. Para Taylor, el caso amoroso de Cardenio, al contrario que la novela de El curioso impertinente, no fue concebido por Cervantes al margen de las aventuras de Don Quijote ${ }^{45}$. Esta situación podría llevarnos a dos procedimientos: el primero sería intentar reconstruir la otra mitad de un supuesto original de Fletcher y Shakespeare al margen de Theobald; el segundo sería perseguir ese objeto con el que historiadores y críticos han fantaseado, un Cardenio que nos permitiera también olvidarnos de Fletcher y que fuese obra de un Shakespeare en plenas facultades literarias. Cualquiera de estos procedimientos pretendería establecer un puente entre el Quijote y The History of Cardenio en el que Theobald, o Fletcher, o ambos, se conciben como males necesarios, o, en definitiva, como estorbos para el encuentro literario entre Shakespeare y Cervantes.

¿Qué exactamente pudo haber encontrado Shakespeare en los episodios cervantinos de Sierra Morena? Lo primero de todo, una estructura literaria en la que los personajes irrumpen en cascada en medio de las circunstancias de don

45 Véase Gary Taylor y John V. Nance, "Four Characters in Search of a Subplot: Quixote, Sancho, and Cardenio", en The Quest for Cardenio, eds. Carnegie y Taylor, pp. 192-213, esp. pp. 192-199. 
Quijote y Sancho. Estos personajes son antes que nada narradores de sus desgracias pasadas, pero también secundarios en la acción principal—las aventuras de don Quijote en Sierra Morena y los intentos del cura y el barbero de devolver a don Quijote a su pueblo. Frente a este encaje, el de Theobald es de una simpleza y de una linealidad que podrían considerarse necesarias en la adaptación de una novela a un esquema dramático. Sin embargo, dos años antes que el perdido Cardenio, Shakespeare había hecho gala del uso del flashback narrativo en The Tempest, una obra que consigue reunir a personajes diversos en un solo espacio a partir de la narración de la experiencia pasada del mago Prospero. Shakespeare bien podría haber ignorado la comodidad de la linealidad cronológica en busca de un argumento más cercano a la complejidad de Cervantes, a la luz de sus últimos romances tragicómicos.

La segunda, al hilo de la desaparición de don Quijote y Sancho del drama de Theobald, es el indudable atractivo que ambos hubieran tenido para Shakespeare. Recientemente Roger Chartrier ha abierto una nueva línea interpretativa de este asunto, basándose en el tratamiento que en 1608 hizo Guillén de Castro, en su comedia Don Quijote de la Mancha, de don Quijote como gracioso y bobo de comedia en una trama de la que, a pesar del título, Cardenio es protagonista ${ }^{46}$. A la luz de textos que dan cuenta de dicho ensamblaje de argumentos, es difícil imaginar a Shakespeare desaprovechando la oportunidad de tratar uno de sus temas favoritos, la locura. Ya en As You Like It , una comedia de 1598, Shakespeare había jugado con la melancolía amorosa del protagonista, Orlando, que, como Cardenio, va dejando huella de su amor en un entorno también agreste y pastoril, el Bosque de Arden, en forma de quejosos sonetos petrarquistas. Más adelante, Shakespeare trató la locura en Hamlet y en King Lear. La primera nos introduce en el fingimiento de un estado mental, pero también en el modo en el que unas circunstancias terribles producen la zozobra psicológica de un héroe. Hamlet, Cardenio y don Quijote nos muestran facetas diferentes del tránsito de la enajenación a la cordura. En King Lear, Shakespeare jugó a confrontar al rey enloquecido por la pérdida de una hija y el engaño de otras dos con la demencia fingida de Edgar. La puesta en esa escena frente a frente de dos tipos diferenciados del loco es algo con lo que Cervantes experimenta en el primer encuentro entre don Quijote y Cardenio. En la desazón y el desaliño de Cardenio, "astroso Caballero de la Sierra" - "roto el vestido y el rostro desfigurado"-podrían buscarse similitudes con la descripción que Ofelia nos brinda de Hamlet:

My lord, as I was sewing in my closet, Lord Hamlet, with his doublet all unbrac'd, No hat upon his head, his stockings fouled, 
Ungarter'd, and down-gyved to his ankle,

Pale as his shirt, his knees knocking each other,

And with a look so piteous un purport

As if he had been loosed out of hell

To speak of horrors-he comes to me.

[Señor, mientras cosía en mi aposento, / aparece ante mí el príncipe Hamlet / con el jubón desabrochado, sin sombrero, / con las calzas sucias y caídas como argollas / al tobillo, más pálido que el lino, / temblando las rodillas, y el semblante / tan triste en su expresión que parecía / huido del infierno para hablar con espantos.] ${ }^{47}$

El exiguo y torpe tratamiento que hace Theobald de Dorotea sorprende también. Recordemos la semblanza que Cardenio adelanta al comienzo de su cuento: "tan hermosa, recatada, discreta y honesta, que nadie que la conocía se determinaba en cuál destas cosas tuviese más excelencia ni más se aventajase" ${ }^{28}$. Difícilmente habría pasado esto inadvertido a Shakespeare. Tampoco las posibilidades de su disfraz de pastor, tan poco explotadas por Theobald, a la luz de heroínas travestidas como Rosalind (As you Like It), Portia (The Merchant of Venice) o Viola (Twelfth Night). Con todas ellas Dorotea comparte el disfraz masculino (y el de pastor con Rosalind). Pero sobre todo comparte discreción, inteligencia, resolución y dignidad ante la adversidad, compasión ante los males ajenos, $y$, más importante de todo, un inquebrantable sentido de la justicia. $\mathrm{Su}$ papel como princesa Micomicona para curar los humores del loco hidalgo habría sido irresistible para Shakespeare. La Violante de Theobald, es, al contrario, melodramática y plañidera.

Finalmente, resulta difícil pensar que Shakespeare no hubiera hecho de la Sierra Morena cervantina un espacio atractivo para dramatizar la locura, el amor, la traición, el perdón, si atendemos al Bosque de Arden en As You Like It, las islas de romance de Twelfth Night y The Tempest, o la naturaleza salvaje y los acantilados de Dover en King Lear. Pensar en un Shakespeare constreñido por la simpleza espacial de Double Falsehood es imaginar a un dramaturgo que renuncia a dotar, como también hace Cervantes, a sus espacios literarios de una fuerte carga simbólica.

En cualquier caso, solamente la especulación y la recreación pueden ayudar, si no a recuperar la perdida The History of Cardenio, sí al menos a hacernos una idea de su contenido. Entre quienes se han lanzado a esta tarea, podría hacerse

47 Cervantes, Don Quijote, ed. Rico, I.23, p. 282, I.24, p. 285; Shakespeare, Hamlet, 2.1.7481, p. 1152. Traducción de Ángel-Luis Pujante, en William Shakespeare, Hamlet. Madrid: Espasa Calpe, 1994, p. 96.

48 Cervantes, Don Quijote, ed. Rico, p. 240. 
referencia al proyecto dirigido por el profesor Stephen Greenblatt entre 2003 y 2012, consistente en la puesta en común de recreaciones libres, multiculturales y multilingües en los cinco continentes ${ }^{49}$. Con un carácter mucho más historicista y académico, un equipo de investigadores liderados por otro ilustre estudioso de la obra de Shakespeare, Gary Taylor, concluyó con la reescritura en 2012 por parte del propio Taylor de The History of Cardenio, en colaboración póstuma, nos dice, con Fletcher y Shakespeare, en un intento de borrar todo rastro de Theobald. Un año antes, el novelista Robin Chapman publicó su "novela dialogada" Shakespearés Don Quixote. Chapman pisaba terreno conocido, pues ya había publicado tres fantásticas secuelas noveladas del Quijote: The Duchess's Diary (1980), Sancho's Golden Age (2004), y Pasamonte's Life (2005). Y antes de todo esto el escritor hispano-cubano José Carlos Somoza había escrito y estrenado Miguel Will (1997), una pieza teatral, descrita por su autor como "farsa", que discurre en torno a los frustrados intentos de un anciano Shakespeare por dar vida a Don Quijote en The History of Cardenio.

Un análisis en profundidad de estas obras desbordaría el objetivo de este trabajo, y tan solo se ofrecen aquí unas pinceladas. La obra de Taylor, representada desde 2005 pero publicada en 2012, se propone "desadaptar" la adaptación de Theobald en un ejercicio que combina la creación literaria con conocimientos de estilística, historia textual e historia del teatro ${ }^{50}$. Taylor respeta la linealidad que encontramos en Theobald, pero revierte todos los nombres a su original cervantino, excepto Dorotea, que ya no es Violante sino Violenta. Sin embargo, Taylor añade una trama secundaria en la que el cura y el barbero intentan devolver a su pueblo al Señor Quesada, un viejo maestro de escuelas enloquecido por la lectura de los libros de caballerías, que ha salido con su sirviente Sancho en busca de aventuras. En un ejercicio inteligente de compresión dramática, Taylor se las arregla para hacer llegar a los oídos del espectador las hazañas de Don Quijote con molinos, galeotes, etc. Sin embargo, decide reducir el contacto entre las dos tramas a dos aspectos: por una parte, un encuentro entre Cardenio y Don Quijote, postergado aquí hasta el acto cuarto, y que parece tener como excusa que Don Quijote acabe molido a palos por interrumpir a Cardenio, como en el original, cuando este intenta contar su historia-una historia que, a diferencia del texto de Cervantes, aquí ya conocemos porque la hemos visto representada en escenas anteriores; por otra parte, la intervención de Violenta, en el papel de

49 Véase Stephen Greenblatt, The Cardenio Project: An Experiment in Cultural Mobility. <http:// www.fas.harvard.edu/-cardenio/>, accessed 28 September 2016). También Carla Della Gatta, "Cultural Mobility and Transitioning Authority: Stephen Greenblatt's Cardenio Project", en The Quest for Cardenio, eds. Carnegie y Taylor, pp. 329-45.

50 Véase Gary Taylor, "The History of Cardenio: 1612-2012", en The Creation and Re-Creation of Cardenio, eds. Bourus y Taylor, pp. 237-316. Taylor expone los principios de su reconstrucción en un texto titulado, de manera reveladora, "A Posthumous Collaborator's Preface", pp. 237-240. 
Princesa Micomicona en el engaño para devolver a Quesada a su pueblo. El efecto es el de una obra tragicómica con un fuerte potencial trágico, pero que la trama quijotesca suaviza con su exagerado tono farsesco. La visión de don Quijote es la esperable en la Inglaterra del XVII: la de un loco monomaníaco y risible ${ }^{51}$.

Taylor recupera a Don Quijote como secundario de Cardenio. Años antes, José Carlos Somoza desechaba esa posibilidad y nos presentaba a un Shakespeare torturado por mostrar lo que se antojaba un imposible para el teatro de su época: un Quijote que dominase de principio a fin su versión de Cervantes y que además fuese "bufón y noble a la vez" ${ }^{52}$, para desesperación de su actor fetiche, Richard Burbage. Ante la negativa de su compañía de aceptar su propuesta, Shakespeare acaba diseñando un argumento para su propio lucimiento como actor-autor: sustituir a un don Quijote que pierde la razón con la lectura de libros de caballerías por Miguel Will, un dramaturgo que enloquece imaginando a sus propios personajes. El fracaso de la idea lleva a la compañía de Shakespeare a sustituir el texto original por una insípida comedia del aprendiz y advenedizo Fletcher. La osadía shakesperiana solo encuentra aprobación en un Cervantes que en la obra no es más que un mero reflejo en el espejo de los aposentos del dramaturgo de Stratford:

Hola, hijo, por si te sirve de consuelo, te diré que yo también estuve en el teatro el famoso día del estreno, y a mí sí me gustó tu obra. No te aplaudí porque soy un fantasma de tu imaginación y porque me falta una mano: dos poderosas razones para no aplaudir, reconócelo. Pero me gustó tu original manera de tratar a mi personaje. Te lo agradezco, Will, sinceramente. ${ }^{53}$

Somoza utiliza la excusa de Cardenio para una pirueta de carácter pirandelliano: aquí es el autor quien busca al personaje. Su tratamiento del encuentro personal de Shakespeare y Cervantes y su encuentro textual en torno a Cardenio prefigura el análisis más complejo de estas dos cuestiones realizado hasta la fecha en la ficción: el Shakespearés Don Quixote de Robin Chapman. En esta "novela" unos fantasmagóricos Shakespeare, Fletcher y Cervantes (a quienes más tarde se une Lewis Theobald) asisten al estreno en el Londres contemporáneo de una producción teatral, titulada "El Quijote de Shakespeare". Esta pieza es una recreación de los episodios cervantinos de Cardenio en un esquema teatral de cinco actos, a la manera renacentista, aunque la escritura es mayoritariamente

51 Sobre este particular véase Clark Colahan, "Shelton and the Farcical Perception of Don Quixote in Seventeenth-Century Britain", en The Cervantean Heritage, ed. J.A.G. Ardila, pp. 61-65.

52 José Carlos Somoza, Miguel Will. Madrid: Fundación Autor, 1997, p. 37.

53 José Carlos Somoza, Miguel Will, p. 85. 
en prosa. En los largos interludios y entreactos, asistimos a los monólogos y diálogos de unos espectadores privilegiados, que nos dan cuenta de la esencia de la narración cervantina, de la intrahistoria del perdido Cardenio, que se atribuye principalmente a Fletcher excepto en la trama secundaria, de tema quijotesco, y de sus diferencias con lo que ellos están presenciando. Esto es al menos lo que observa un vanidoso e indignado Fletcher, que reivindica la paternidad de la criatura:

I would urge the present writer ... to concentrate, as William and I did, on the knight and squire as sub-plot, not, repeat not main plot. Use them as comic relief, happy cutaways from the quadruple romance thrust...

[Apremiaría al escritor moderno ... a concentrarse, como William y yo hicimos, en el caballero y el escudero como trama secundaria, no, repito, no como trama principal. A utilizarlos como alivio cómico, como feliz cambio de plano con respecto al foco romántico $]^{54}$

Sin embargo, Fletcher se ve poco a poco arrinconado por la buena sintonía entre los dos genios, que van descubriendo cómo en esa vida después de la muerte que Chapman les concede han ido desarrollando una gran admiración mutua de la que no pudieron disfrutar en su primera vida. Sobre la obra que están viendo, Cervantes se queja sobre su carácter demasiado cervantino (algo que en vida del autor nunca fue garantía de éxito teatral $)^{55}$. Aunque Shakespeare parece aplaudir su sentido:

Well, naturally I can't help comparing it with my version and Jack's. And, as has been said, he made the most of the romance action while cutting back on the comedy. Here it's the other way round. I can see why. Your knight and squire's presumptions can still find comic parallels today whereas the niceties of betrothal contracts or interrupted wedding ceremonies are more difficult to dramatise however central they may be to the action.

[Bueno, naturalmente que no puedo evitar compararla con mi versión y la de Jack. Como se ha dicho, él se encargó de la mayor parte de la acción romántica, recortando la comedia. Aquí es justo al revés. Y puedo entender por qué. Las opiniones de vuestro caballero y escudero todavía encuentran paralelismos cómicos hoy, mientras

54 Robin Chapman, Shakespeare's Don Quixote. Londres: Now, 2011, p. 65.

55 Chapman, Shakespeare's Don Quixote, p. 102. 
que las sutilezas de los compromisos matrimoniales y los esponsales interrumpidos son más difíciles de dramatizar, a pesar de ser más pertinentes para la acción. $]^{56}$

Con el acompañamiento de largas acotaciones explicativas, Chapman pone frente al lector el texto dramático íntegro de esta imaginaria y modernizada The History of Cardenio. Como nos dice en su Prólogo, se propone una obra para ser escenificada en "la caja negra" del "teatro de la mente" ${ }^{57}$. Este nuevo Cardenio está menos atado al lenguaje y a las condiciones de su medio dramático original-el predominio de la prosa sobre el verso es la mejor muestra de ello. Para ello, su propuesta es diferente a la mutilación perpetrada por Theobald o a la reconstrucción académica, de corte más fletcheriano, que presenta Gary Taylor. Chapman, a pesar de las muchas limitaciones de su esquema, quiere imaginar un Cardenio como Shakespeare lo hubiera diseñado a partir de Cervantes. En su versión observamos que la obra comienza con las nupcias fallidas de Fernando y Dorotea, con la retirada de esta al convento y la huida de Cardenio. En la linealidad del diseño de Theobald y de Taylor, este momento se lleva al acto tercero. De los esponsales saltamos a la llegada de don Quijote y Sancho a Sierra Morena y al encuentro con Cardenio. Chapman recupera así el flashback, para Cardenio primero y para Dorotea después. De esa manera inserta en el medio teatral la importancia que Cervantes da a su papel como narradores: lo que, por otra parte, y como se ha apuntado, Shakespeare ensayó ya en The Tempest. La tensión entre Cardenio y Don Quijote se muestra irresistible para un tratamiento teatral. Y salta en pedazos aquí la idea de constreñir a don Quijote a la trama secundaria. El protagonista de Cervantes se hace con las riendas de la obra. Y así se convierte en el Quijote, y no simplemente en el Cardenio de Shakespeare. Además, el teatro dentro de la novela, unido a los diálogos entre Shakespeare y Cervantes sobre estos géneros, nos da una idea de la intención de Chapman: el vínculo de un Shakespeare y un Cervantes en plenitud en torno al Cardenio debería tener lugar en un maridaje ideal de estas formas literarias. Al fin y al cabo, sabemos que Cervantes ansió el éxito sobre las tablas de sus obras dramáticas ${ }^{58}$. Y hemos apuntado brevemente aquí que la escritura teatral del último Shakespeare, sobre todo de Pericles en adelante, camina hacia formas de expresión cada vez más cercanas a la narratividad. En definitiva, este ensamblaje de elementos permite a

56 Chapman, Shakespeare's Don Quixote, p. 212.

57 "Welcome to the theatre of my mind. Think of it as I do. As a black box. A space in which the past can become the present at the turn of a phrase or the drop of a hat". Chapman, Shakespeare's Don Quixote, p. 1.

58 Mucho se ha escrito sobre estas ansias del Cervantes dramaturgo. Una excelente síntesis reciente puede encontrarse en el primer capítulo de Ignacio García Aguilar, Luis Gómez Canseco y Adrián J. Sáez, El teatro de Miguel de Cervantes. Madrid: Visor, 2106, pp. 13-31. 
Chapman convertir al Cardenio en la ocasión perfecta para una reunión de genios que es a su vez una celebración por todo lo alto del poder de la literatura.

\section{Coda: Borges, el legado de Cervantes, y la memoria de Shakespeare}

En uno de sus últimos relatos, "La memoria de Shakespeare" (1983), Jorge Luis Borges se preguntaba lo siguiente:

Quien adquiere una enciclopedia no adquiere cada línea, cada párrafo, cada página y cada grabado; adquiere la mera posibilidad de conocer alguna de esas cosas. Si ello acontece con un ente concreto y relativamente sencillo, dado el orden alfabético de las partes, ¿qué no acontecerá con un ente abstracto y variable, ondoyant et divers, como la mágica memoria de un muerto?59

La pregunta y la respuesta corren a cargo del narrador, Hermann Soergel, un gris académico alemán especialista en la obra de Shakespeare que durante un congreso acepta de un colega un regalo inesperado: la memoria del poeta. El preciado don se va instalando poco a poco en la conciencia de Soergel, quien nos revela sus recién estrenados recuerdos: el de los rostros de los poetas George Chapman y Ben Jonson, pero también el de un anónimo vecino del poeta, no mencionado en las biografías o en las historias literarias. También la poca pericia de Shakespeare para recitar hexámetros latinos, y sus razones para introducir, de manera deliberada, inconsistencias y anacronismos en sus dramas. Y muchas otras circunstancias, fascinantes algunas e insustanciales o decepcionantes la mayoría, que poco a poco se van confundiendo con la memoria del propio Soergel y anulando su identidad, y que ni siquiera le proporcionan un material valioso para emprender una biografía del poeta:

La memoria de Shakespeare no podía revelarme otra cosa que las circunstancias de Shakespeare. Es evidente que éstas no constituyen la singularidad del poeta: lo que importa es la obra que ejecutó con ese material deleznable. ${ }^{60}$

No sabemos si el nombre de Cervantes fue siquiera una pequeña gota en el infinito caudal de la memoria de Shakespeare: Tampoco si las desventuras y posteriores fortunas de Cardenio constituyeron alguna vez una entrada de esa enciclopédica memoria. Las recreaciones de la obra son quizás un intento borgiano de superponer el contenido de esa memoria perdida sobre la nuestra propia.

59 Borges, "La memoria de Shakespeare", Obras completas, vol. II, pp. 391-397. p. 395.

60 Borges, "La memoria de Shakespeare", p. 395. 
Además, el acercamiento de Shakespeare a Cervantes a través de la perdida, reescrita, recreada y re-imaginada The History of Cardenio nos haría preguntarnos si no estamos intentando convertir a Shakespeare en una suerte de precursor del Pierre Menard borgiano, capaz de suplantar el texto cervantino y presentarlo, casi por arte de magia, listo para una ocasión teatral digna de Hamlet, Othello, o The Tempest. Solo es casualidad que Borges recurra a una frase del capítulo 26, en medio de la penitencia de don Quijote en Sierra Morena, en este momento de su conocido relato:

¿Confesaré... que leo el Quijote-todo el Quijote—como si lo hubiera pensado Menard? Noches pasadas, al hojear el capítulo XXVI—no ensayado nunca por él—reconocí el estilo de nuestro amigo y como su voz en esta frase excepcional: las ninfas, los rios, la dolorosa y húmida Eco.

Esa conjunción eficaz de un adjetivo moral y otro físico me trajo a la memoria un verso de Shakespeare, que discutimos más tarde:

Where a malignant and a turbaned Turk. ${ }^{61}$

La sutileza lectora y la imaginación creadora de Borges propician un encuentro estilístico entre Cervantes y Shakespeare en la pluma de un escritor ficticio, Menard, al que se presenta como lector de ambos. A falta de textos y testimonios (a falta, a fin y al cabo, de memoria), el encuentro entre Cervantes y Shakespeare es patrimonio exclusivo de sus más avezados lectores.

61 Borges, "Pierre Menard", p. 447. Véase la frase cervantina en su contexto en Don Quijote, ed. Rico, I.26, p. 321. Y el verso shakesperiano, en el momento final de Othello, 5.2.353, p. 1240. 
